\title{
Red propolis hydroalcoholic extract inhibits the formation of Candida albicans biofilms on denture surface
}

\author{
Karla-Lorene-de França Leite 1, Mariana-Leonel Martins 1, Mariana-Marinho-Davino de Medeiros ${ }^{2}$, Nata- \\ nael-Victor-Furtunato Bezerra ${ }^{3}$, Camila-Santos-de Mattos Brito ${ }^{3}$, Leopoldina-de Fátima-Dantas de Almeida ${ }^{3}$, \\ Yuri-Wanderley Cavalcanti ${ }^{3}$
}

\footnotetext{
${ }^{1}$ Department of Pediatric Dentistry and Orthodontics, School of Dentistry, Federal University of Rio de Janeiro, Rio de Janeiro, RJ, Brazil

${ }^{2}$ Department of Prosthodontics and Periodontology, Piracicaba Dental School, University of Campinas, Piracicaba, SP, Brazil

${ }^{3}$ Department of Clinical and Social Odontology, Federal University of Paraíba, João Pessoa, PB, Brazil
}

Correspondence:

Department of Clinical and Social Dentistry

Federal University of Paraiba

UFPB Campus I

Cidade Universitária

João Pessoa, PB

CEP 58051-900, Brazil

yuri@ccs.ufpb.br

Leite KLF, Martins ML, de Medeiros MMD, Bezerra NVF, Brito CSM, de Almeida LFD, Cavalcanti YW. Red propolis hydroalcoholic extract inhibits the formation of Candida albicans biofilms on denture surface. J Clin Exp

Received: $28 / 01 / 2020$

Accepted: 26/04/2020 Dent. 2020;12(7):e626-31.

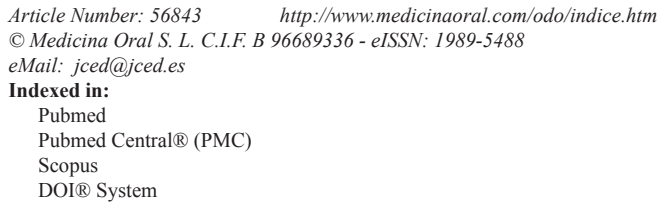

\begin{abstract}
Background: To evaluate the antifungal activity of the red propolis hydroalcoholic extract (RPHE) against Candida albicans biofilms.

Material and Methods: The minimum inhibitory and fungicidal concentrations (MIC and MFC) of the RPHE were determined by the microdilution technique. C. albicans biofilms were formed on the surface of resin specimens preconditioned with artificial saliva $(1 \mathrm{~h})$. The specimens $(\mathrm{N}=48)$ were equally divided according to the four solutions used for anti-biofilm evaluation ( $\mathrm{n}=12$ per group). After overnight incubation, biofilms were daily exposed ( $2 \mathrm{x} /$ day for $15 \mathrm{~min}$ ) along 3 days with 3\% RPHE, $0.12 \%$ chlorhexidine (CHX), 50,000 IU/mL nystatin (NYS) or saline $(0.9 \% \mathrm{NaCl})$. Biofilms were analyzed regarding the number of viable microorganisms $(\mathrm{CFU} / \mathrm{mL})$, the metabolic activity (MTT assay) and the proportion of hyphae (optical microscopy).

Results: The MIC and MFC of RPHE were respectively $0.29 \mathrm{mg} / \mathrm{mL}(0.03 \%)$ and $1.17 \mathrm{mg} / \mathrm{mL}(0.12 \%)$. There was no difference in the microorganisms' viability $(\mathrm{CFU} / \mathrm{mL})$ among groups treated with RPHE $(4.92 \times 103)$, CHX $(3.33 \times 102)$ or NYS $(6.8 \times 104)$, being all of them different from NaCl $(3.93 \times 107)(p<0.05)$. The CHX $(0.133)$ had the lowest metabolic activity $(p<0.05)$, followed by RPHE (0.292) and NYS (0.302) $(p>0.05)$. All experimental groups had a mean proportion of hyphae $<10 \%$, lower than $\mathrm{NaCl}(70 \%)$.

Conclusions: RPHE has antifungal activity against $C$. albicans biofilms, suggesting its use for the biofilm control on denture surfaces.
\end{abstract}

Key words: Propolis, Candida albicans, biofilm, dentures, antifungal agents. 


\section{Introduction}

Oral candidiasis is an opportunistic infection related to the excessive proliferation of Candida, as a result of the homeostatic imbalance of oral microbiota (1). In many cases, Candida infection is associated with the use of removable dentures, especially among denture wearers who are not able to maintain satisfactory hygiene of their prosthesis $(2,3)$.

Denture cleaning solutions are frequently recommended for the treatment of such infections, associated or not with the use of local antifungals $(3,4)$. The efficacy of antifungal agents has been proven by a systematic review of the literature (5). Although the efficacy of denture cleansing solutions is also proven in the literature, new alternatives remain in constant development (4). Moreover, the preventive effect of these solutions has been little explored in the literature (4).

In general, recurrence of denture stomatitis may occur due to discontinuation of antifungal therapy and microbial resistance $(6,7)$. Methods for cleaning prosthetic surfaces may reduce the accumulation of biofilm, but do not prevent recolonization (8). In addition, they may compromise the longevity of dentures by promoting surface changes such as abrasion and increased roughness (9).

Natural products have promoted the search for therapeutic possibilities that are biocompatible and accessible to the population in order to overcome these limitations $(10,11)$. Red propolis, mainly formed by the botanical compounds extraction of Dalbergia ecastophyllum from Apis mellifera bees, presents phenolic compounds, especially flavonoids. These phytochemicals are associated with antifungal activity (12) and make this product a promising natural antimicrobial agent (13-15).

Red propolis extract has been shown to control the imbalance of oral microbiota homeostasis by reducing the proliferation of Candida (16), as well as being a biocompatible substance compared to synthetic antimicrobials $(17,18)$, which may have undesirable effects, such as microbial resistance (19).

Thus, there is a need to evaluate its antifungal activity, with the purpose of presenting an alternative for the treatment of fungal infections. Therefore, the aim of this study was to evaluate the antifungal activity of the red propolis hydroalcoholic extract (RPHE) against C. albicans biofilms developed on the surface of denture base material.

\section{Material and Methods}

-Ethics information

This study did not involve human participants or material collected from human (i.e.: saliva). Biofilms were developed in the presence of artificial saliva. Microorganisms samples used in this study were derived from standardized strains cultured in laboratory.
-Red Propolis Hydroalcoholic Extract

The red propolis hydroalcoholic extract (RPHE) was obtained in the concentration of $30 \%$, provided by Apiário Edimel located in the town of João Pessoa, Brazil (Lati-

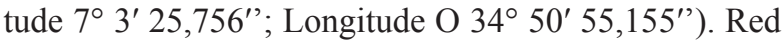
propolis was collected within the Brazilian spring period $\left(23^{\circ}-30^{\circ}\right)(18)$. The RPHE was used in its commercial presentation $(30 \% \mathrm{w} / \mathrm{v}$, or $300 \mathrm{mg} / \mathrm{mL})$ for the determination of Minimum Inhibitory Concentration (MIC). For anti-biofilm assays, the RPHE concentration was based on MIC and on a $10 \times$ dilution of its commercial form.

-Standardization of Inoculum

Candida albicans (ATCC 90028) was reactivated in Petri dishes (Alamar ${ }^{\mathrm{TM}}$, Diadema, BRA) containing Sabouraud Dextrose agar (Himedia Laboratories ${ }^{\mathrm{TM}}$, Mumbai, India) and incubated at $37^{\circ} \mathrm{C}$ for 48 hours. The inoculum was standardized in RPMI 1640 (Aldrich Chemical Co., St. Louis, USA) using a spectrophotometer (Lgi Scientific $^{\mathrm{TM}}$, São Paulo, BRA). An optical density of 0.1 , under $600 \mathrm{~nm}$ wavelength, was set to obtain the concentration of $5 \times 10^{6} \mathrm{CFU} / \mathrm{mL}$ (20). The final concentration of the inoculum for MIC and biofilm assays were $5 \times 10^{3}$ and $1 \times 10^{5} \mathrm{CFU} / \mathrm{mL}$, respectively.

-Antifungal Activity

The antifungal activity was determined by means of the minimum inhibitory concentration (MIC), in which a microdilution assay was carried out in a 96-well microtiter plate (Alamar ${ }^{\mathrm{TM}}$, Diadema, São Paulo, BRA), according to M27A3 from CLSI (20). RPHE (30\% w/v) and $0.12 \%$ chlorhexidine (used as control) were diluted and then $100 \mu \mathrm{L}$ of the inoculum was inserted into all wells, except in the line corresponding to the sterility control. Final concentrations ranged from 75 to $0.0366 \mathrm{mg} / \mathrm{mL}$ for RPHE and from 0.3 to $0.000146 \mathrm{mg} / \mathrm{mL}$ for CHX. After the incubation period in aerobiosis $\left(24 \mathrm{~h}\right.$ at $\left.37^{\circ} \mathrm{C}\right)$, the MIC corresponded to the last dilution of the RPHE in which the presence of microbial precipitate or turbidity in the culture medium after the incubation period was not verified. The determination of MIC was confirmed by the use of $3 \mathrm{mM}$ Resazurin (Sigma, ST. Louis, MO, USA). Resazurin is a colorimetric indicator of cellular respiration, which when in blue represents a state of oxidation and becomes pink when reduced by viable cells detection without the use of a spectrophotometer (21). After incubation for $4 \mathrm{~h}$, the results were visualized by the visual method.

The minimum fungicidal concentration (MFC) was obtained by seeding of $50 \mu \mathrm{L}$ aliquots of dilutions equal to or greater than MIC. Then, Sabouraud Dextrose plates incubated with $\mathrm{MIC}$ aliquots were incubated at $37{ }^{\circ} \mathrm{C}$ for $24 \mathrm{~h}$. The MFC was considered the lowest concentration of the substance that prevented the visible growth of the subculture, or the formation of up to three Colony Forming Units (CFU) (22). The tests for determination of MIC and MFC were performed in triplicate. 
-Anti-biofilm Activity

Anti-biofilm activity was evaluated after developing biofilms on the surface of denture base material. Resin specimens made of polymethylmethacrylate (PMMA) (QC-20, Dentsply Int Inc ${ }^{\mathrm{TM}}$, Weybridge, UK) were obtained from prefabricated stainless-steel molds of circular shape (10 $\mathrm{mm}$ diameter, $2 \mathrm{~mm}$ thickness). The resin was handled according to the manufacturer's recommendations and inserted from the stainless-steel molds, using a pressure of $1000 \mathrm{~N}$. Polymerization was by immersion in boiling water for $20 \mathrm{~min}$, followed by slow cooling. The specimens were kept in distilled water to release residual monomer for $48 \mathrm{~h}$. The selection of specimens occurred after polishing with silicon carbide sandpaper in \#400 and \#600 granulation. Specimens that presented blisters or roughness were discarded. The specimens $(\mathrm{N}=48)$ were autoclaved $\left(121^{\circ} \mathrm{C}, 15 \mathrm{~min}\right)$ immersed in distilled water solution. Then, they were equally divided according to the four solutions used for anti-biofilm evaluation ( $\mathrm{n}=12$ per group).

Prior to biofilm formation, the specimens were submitted to the formation of artificial salivary pellicle (23), with $1 \%$ carboxymethyl, $0.0084 \%$ sodium chloride, $0.12 \%$ potassium chloride, $0.0342 \%$ phosphate monobasic potassium, $0.0146 \%$ calcium chloride, and $0.0052 \%$ magnesium chloride. Specimens were then incubated at $37^{\circ} \mathrm{C}$ for $2 \mathrm{~h}$, in 24 -well polystyrene culture plates (model K12-024, Kasvi ${ }^{\mathrm{TM}}$, São José do Pinhais, BRA). After saliva removal, $2 \mathrm{~mL}$ of the $C$. albicans inoculum was inserted. The specimens were then incubated in the presence of the inoculum at $37^{\circ} \mathrm{C}$ for $24 \mathrm{~h}$.

After this period, the specimens were individually submitted to treatment (specimen's immersion, $2 \mathrm{~mL}$ ) with one of the antimicrobial solutions evaluated in this study: 3\% RPHE (based on MIC and on a $10 \times$ dilution of RPHE's commercial presentation), $0.12 \%$ Chlorhexidine (CHX), 50,000 IU/mL Nystatin (NYS) and 0.9\% Sodium Chloride $(\mathrm{NaCl})$. The treatments were performed twice a day (8:00 am and 4:00 pm) for 3 days, during $15 \mathrm{~min}$. After exposure to the solutions, the specimens were washed in saline solution $(2 \times)$ and the culture medium was renewed.

After $72 \mathrm{~h}$, specimens were individually transferred to microtubes containing $1 \mathrm{~mL}$ saline. Specimens were then vortexed during $1 \mathrm{~min}$ for biofilm disruption. Aliquots of suspended cells were used for quantification of viable microorganisms, hyphae quantification and assessing the metabolic activity.

For quantification of number of viable microorganisms, the suspension of cells were serially diluted $\left(10^{-1}\right.$ to $\left.10^{-6}\right)$ and $10 \mu \mathrm{l}$ aliquots were seeded (triplicate) on Sabouraud Dextrose agar and incubated at $37^{\circ} \mathrm{C}$ for $48 \mathrm{~h}$. After this period, the count of colony forming units $(\mathrm{CFU} / \mathrm{mL})$ was verified. The suspension of cells was also analyzed under an optical microscope using a $100 \times$ objective $\left(\right.$ Carl Zeiss ${ }^{\mathrm{TM}}$,
Oberkochen, DEU), in order to determine the proportion of hyphae. For this purpose, each slide containing biofilm precipitate was analyzed in at least three different points.

Metabolic activity was assessed by the soluble MTT assay 3-[(4,5-dimethylthiazol-2-yl) -2,5-diphenyltetrazolium bromide] as described by Loures and Levitz (2015) (24), with modifications. The suspended cells from the biofilms were centrifuged for $5 \mathrm{~min}$ (Cientec ${ }^{\mathrm{TM}}$, Belo Horizonte, BRA). After that, the supernatant was eliminated and $500 \mu \mathrm{L}$ of MTT solution was added to microtubes, followed by incubation $\left(37^{\circ} \mathrm{C}, 4 \mathrm{~h}\right)$, without exposure to light. The microtubes were then centrifuged again (5 $\mathrm{min}$ ) to remove the supernatant. After that, the precipitated was treated with acid alcohol $(350 \mu \mathrm{L})$ and absorbance was read in a spectrophotometer $(490 \mathrm{~nm})$. -Data Analysis

The results of MIC, MFC and hyphae ratio were tabulated using Microsoft Office Excel $2007^{\mathrm{TM}}$ and analyzed descriptively. SPSS software version 20.0 (IBM ${ }^{\mathrm{TM}}$, Chicago, USA) was used considering a $5 \%$ significance level. The non-normal distribution was verified by the Shapiro-Wilk test. The Kruskal-Wallis and Mann-Whitney tests were used to evaluate the number of viable microorganisms and metabolic activity.

\section{Results}

The MIC and MFC of the RPHE were respectively 0.29 $\mathrm{mg} / \mathrm{mL}(0.03 \%)$ and $1.17 \mathrm{mg} / \mathrm{mL}(0.12 \%)$. The CHX $0.12 \%$ showed fungicidal action in all concentrations tested. Sterility and growth controls indicated, respectively, absence of culture medium contamination and viability of the strains tested.

There was no statistically significant difference $(p>0.05)$ for the number of viable cells among RPHE $(4.92 \times 103 \mathrm{CFU} / \mathrm{mL})$, CHX $(3.33 \times 102 \mathrm{CFU} / \mathrm{mL})$ and NYS $(6,8 \times 104 \mathrm{CFU} / \mathrm{mL})$, although those differed from control $(3.93 \times 107 \mathrm{CFU} / \mathrm{mL})(p<0.05)$ (Fig. 1). Control group biofilm $(\mathrm{NaCl})$ presented $70 \%$ hyphae, whilst the groups exposed to RPHE, CHX and NYS presented less than $10 \%$ (Fig. 2).

Compared to control (100\%), the lowest metabolic activity was observed in the group exposed to CHX $(22.23 \%)(p<0.05)$. RPHE $(48.82 \%)$ and NYS $(50.43 \%)$ also reduced the metabolic activity and differed significantly from control and CHX ( $p<0.05)$ (Fig. 3).

\section{Discussion}

The present study demonstrated that the red propolis hydroalcoholic extract inhibited the activity of $C$. albicans, in its planktonic and biofilm form. The RPHE activity was considered satisfactory $(0.29 \mathrm{mg} / \mathrm{mL})$, since excellent MIC values for natural products were found below $0.1 \mathrm{mg} / \mathrm{mL}$ (25). A previous study confirmed the antimicrobial activity of other red propolis extract against 


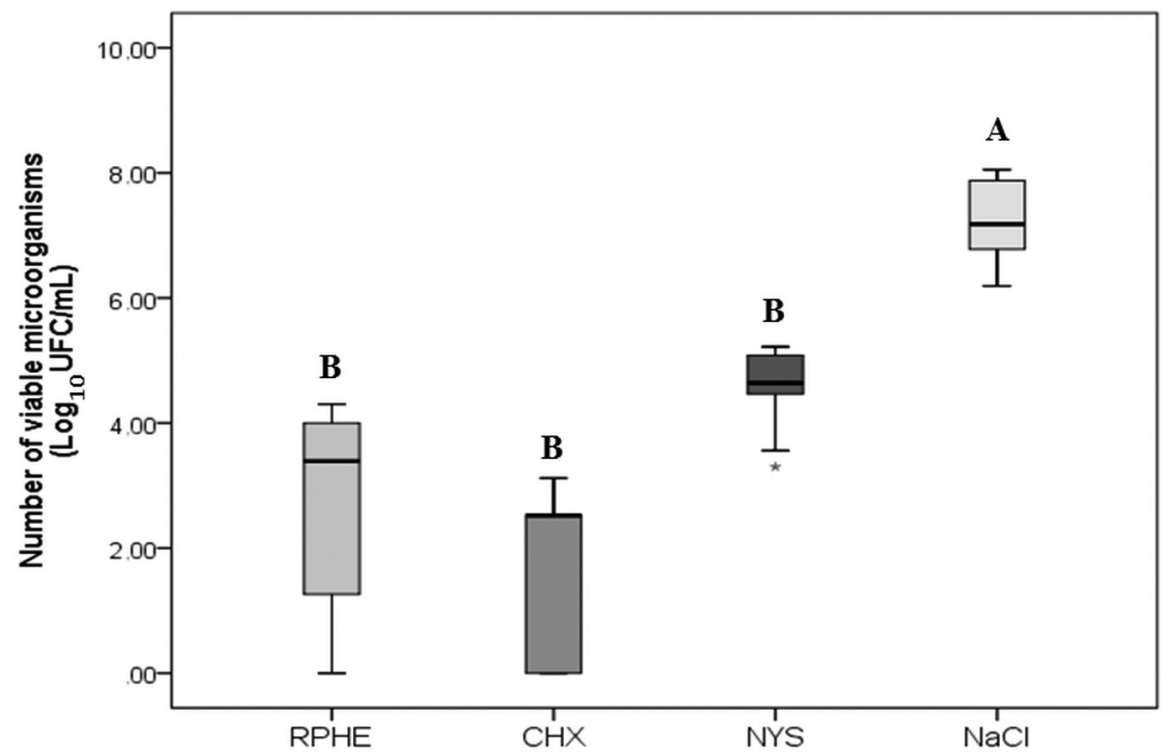

Fig. 1: Fungal viability $\left(\log _{10} \mathrm{UFC} / \mathrm{mL}\right)$ in biofilms after treatments. Different letters indicate statistically significant differences between the groups ( $p<0.05$, Kruskal-Wallis and Mann-Whitney).

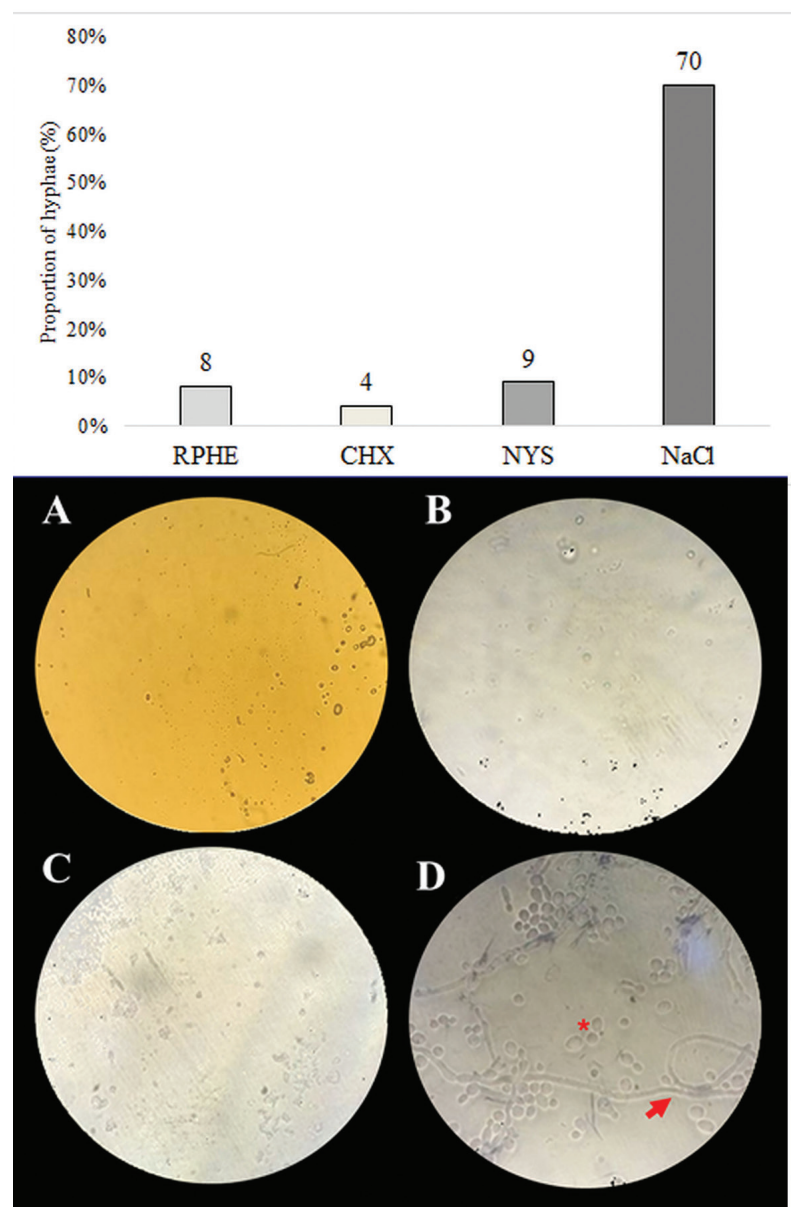

Fig. 2: Proportion of hyphae in relation to the quantitative of yeasts in biofilms after treatments. Photomicrography of C. albicans biofilms after the end of the experimental protocol to the test products, at $1000 \times$ magnification. $\mathrm{A}=\mathrm{RPHE}, \mathrm{B}=\mathrm{CHX}, \mathrm{C}=\mathrm{NYS}$ and $\mathrm{D}=$ $\mathrm{NaCl}$. The asterisk $(*)$ represents yeast structures and the arrow represents filamentous structures (hyphae).
Candida resistant to fluconazole (19), suggesting that the propolis extract could be a promising antimicrobial agent. Results of present study corroborate with this previous finding (19) and added more evidence about the therapeutic potential of a RPHE against Candida infections. According to our data, the RPHE reduced the proliferation of viable microorganisms and also decreased the presence of hyphae within the Candida biofilm.

The RPHE evaluated in the present study is commercially available from the apiary at a concentration of $30 \%$. The anti-biofilm assays were performed at $3 \%$ concentration, corresponding to $\mathrm{MIC} \times 100$ and to $10 \times$ dilution of its commercial presentation. The increased concentration of RPHE (compared to MIC) is due to the robust structure of biofilms, which may influence the resistance compared to planktonic cells (26).

Although there is no consensus attesting to the efficacy of natural products in the treatment of fungal infections (27), indiscriminate use may result in changes that affect application safety (28). On the other hand, the RPHE can be considered promising since the results found for the metabolic activity were similar to nystatin. In addition, the same RPHE (3\%) was evaluated in another study that considered acceptable its use in cytotoxicity in cells of fibroblasts (L-929), as their use for 1 minute was able to maintain $43 \%$ viable cells (18).

The low cytotoxicity demonstrated by RPHE does not impair its recommendation as a mouthwash or denture cleanser (18). The biofilm model in this study validates its effect for decontamination of dental prostheses, without contact with the oral mucosa. It is still necessary to carry out new studies using different concentrations of the product and with a longer exposure time to evaluate the effect on the color change on the surfaces of dental prostheses (29). 


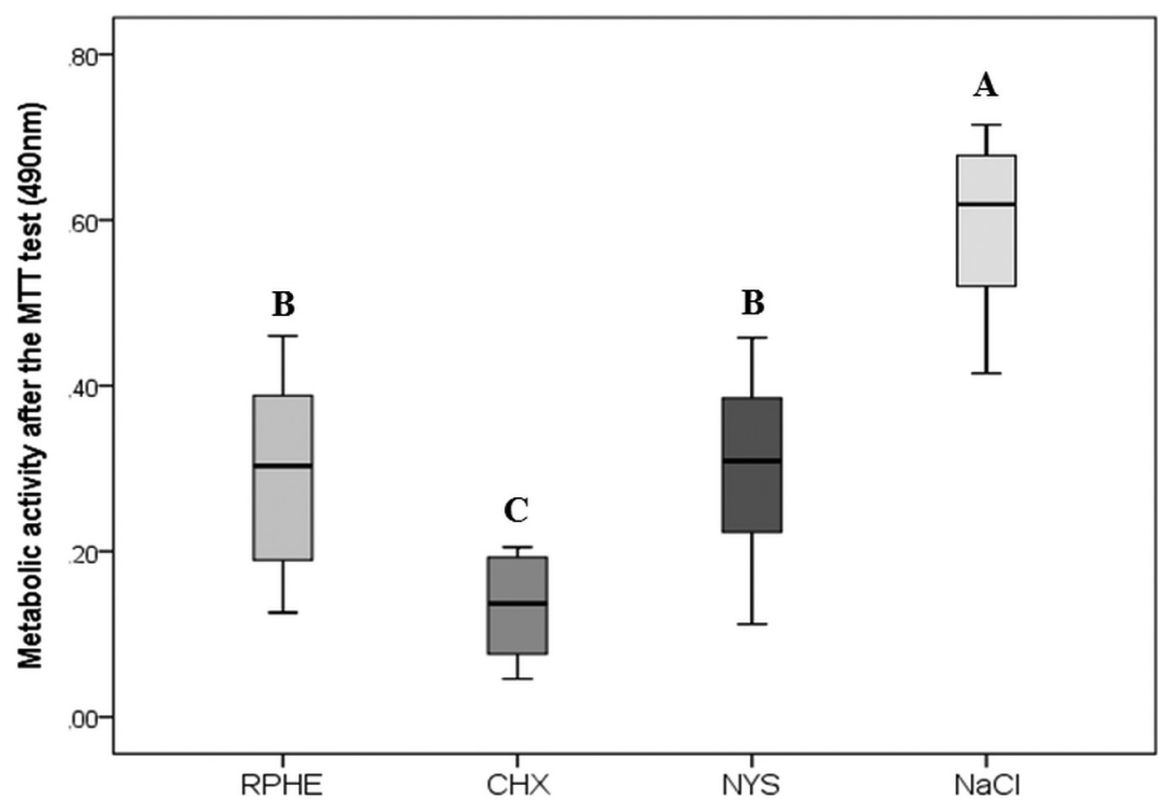

Fig. 3: Metabolic activity after the MTT test. Different letters indicate statistically significant differences between the groups ( $p<0.05$, Kruskal-Wallis and Mann-Whitney).

Red propolis and nystatin reduced the metabolic activity at controlled levels of cell proliferation, indicating that those substances have potential for biofilm inhibition. Possibly this similar action between RPHE and nystatin is due to the lower concentration used in the present study, since at 100,000 IU nystatin can cause an increase in roughness and loss of resin hardness when used in up to 15 days (30). The biofilm control through inhibition of cell proliferation is considered effective against oral infections $(4,6)$. All treatment substances evaluated in the present study reduced the number of hyphae present in this biofilm, therefore affecting the complexity and virulence of this microbial community (7).

This in vitro study suggests that red propolis extract should be further investigated so that it can be used on disinfection of removable dentures. The number of specimens per group in this study is in accordance with previous investigations $(8,18)$. However, larger sample size is strongly recommended for confirming results. In addition, treatment duration is an aspect that should be improved in future investigations. The number of treatment expositions per day, the duration of expositions and the number of days under treatment can be modified in order to simulate clinical use of the RPHE as a denture cleanser.

Therefore, this study stimulates further investigations that could validate the clinical use of RPHE. Conventional cleansing agents can influence the microbial resistance and promote surface alterations, such as abrasion and the roughness, that decrease the longevity of dentures $(1,9)$. Although we did not evaluate the effects of these treatments on the mechanical properties of PMMA resin, we observed that RPHE could be indicated as an effective cleansing agent for the control of Candida biofilms.

\section{Conclusions}

The red propolis hydroalcoholic extract has antifungal activity against $C$. albicans biofilms, suggesting its use for the control of denture biofilms.

\section{References}

1. Chin VK, Lee TY, Rusliza B, Chong PP. Dissecting Candida albicans Infection from the Perspective of C. albicans Virulence and Omics Approaches on Host-Pathogen Interaction: A Review. Int J Mol Sci. 2016;17:E1643.

2. Emami E, Taraf H, de Grandmont P, Gauthier G, de Koninck L, Lamarche $\mathrm{C}$, et al. The association of denture stomatitis and partial removable dental prostheses: a systematic review. Int J Prosthodont. 2012;25:113-119.

3. de Souza RF, de Freitas Oliveira Paranhos H, Lovato da Silva CH, Abu-Naba'a L, Fedorowicz Z, Gurgan CA. Interventions for cleaning dentures in adults. Cochrane Database Syst Rev. 2009:CD007395.

4. Hilgert JB, Giordani JM, de Souza RF, Wendland EM, D'Avila OP, Hugo FN. Interventions for the Management of Denture Stomatitis: A Systematic Review and Meta-Analysis. J Am Geriatr Soc. 2016;64:2539-2545.

5. Zhang LW, Fu JY, Hua H, Yan ZM. Efficacy and safety of miconazole for oral candidiasis: a systematic review and meta-analysis. Oral Dis. 2016;22:185-195.

6. Skupien JA, Valentini F, Boscato N, Pereira-Cenci T. Prevention and treatment of Candida colonization on denture liners: a systematic review. J Prosthet Dent. 2013;110:356-362.

7. Jackson S, Coulthwaite L, Loewy Z, Scallan A, Verran J. Biofilm development by blastospores and hyphae of Candida albicans on abraded denture acrylic resin surfaces. J Prosthet Dent. 2014;112:988-993. 8. Faot F, Cavalcanti YW, Mendonça e Bertolini M, Pinto L de R, da Silva WJ, Cury AA. Efficacy of citric acid denture cleanser on the Candida albicans biofilm formed on poly(methyl methacrylate): effects on residual biofilm and recolonization process. BMC Oral Health. 2014;14:77. 
9. Ragher M, Prabhu UM, Ittigi JP, Naik R, Mahesh CS, Pradeep MR. Efficacy of Denture Cleansers on Impact Strength of Heat polymerized Acrylic Resins. J Pharm Bioallied Sci. 2017;9:S241-S5.

10. Sen T, Samanta SK. Medicinal plants, human health and biodiversity: a broad review. Adv Biochem Eng Biotechnol. 2015;147:59-110. 11. Challinor VL, Bode HB. Bioactive natural products from novel microbial sources. Ann N Y Acad Sci. 2015;1354:82-97.

12. Xie Y, Yang W, Tang F, Chen X, Ren L. Antibacterial activities of flavonoids: structure-activity relationship and mechanism. Curr Med Chem. 2015;22:132-149.

13. Inui S, Hatano A, Yoshino M, Hosoya T, Shimamura Y, Masuda S, et al. Identification of the phenolic compounds contributing to antibacterial activity in ethanol extracts of Brazilian red propolis. Nat Prod Res. 2014;28:1293-1296.

14. Freires IA, de Alencar SM, Rosalen PL. A pharmacological perspective on the use of Brazilian Red Propolis and its isolated compounds against human diseases. Eur J Med Chem. 2016;110:267-279. 15. Silva FRG, Matias TMS, Souza LIO, Matos-Rocha TJ, Fonseca $\mathrm{SA}$, Mousinho KC, et al. Phytochemical screening and in vitro antibacterial, antifungal, antioxidant and antitumor activities of the red propolis Alagoas. Braz J Biol. 2018:S1519-69842018005029101.

16. das Neves MV, da Silva TM, Lima EO, da Cunha EV, Oliveira EJ. Isoflavone formononetin from red propolis acts as a fungicide against Candida sp. Braz J Microbiol. 2016;47:159-166.

17. Lopez BG, de Lourenço CC, Alves DA, Machado D, Lancellotti M, Sawaya AC. Antimicrobial and cytotoxic activity of red propolis: an alert for its safe use. J Appl Microbiol. 2015;119:677-87.

18. Martins ML, Leite KLF, Pacheco-Filho EF, Pereira AFM, Romanos MTV, Maia LC, et al. Efficacy of red propolis hydro-alcoholic extract in controlling Streptococcus mutans biofilm build-up and dental enamel demineralization. Arch Oral Biol. 2018;93:56-65.

19. Pippi B, Lana AJ, Moraes RC, Güez CM, Machado M, de Oliveira $\mathrm{LF}$, et al. In vitro evaluation of the acquisition of resistance, antifungal activity and synergism of Brazilian red propolis with antifungal drugs on Candida spp. J Appl Microbiol. 2015;118:839-850

20. Clinical and Laboratory Standards Institute (CLSI). Reference Method for Broth Dilution Antifungal Susceptibily Testing of Yeasts; Approved Standard - Third Edition. CLSI document M27-A3. Wayne PA, 2008.

21. Sarker SD, Nahar L, Kumarasamy Y. Microtitre plate-based antibacterial assay incorporating resazurin as an indicator of cell growth, and its application in the in vitro antibacterial screening of phytochemicals. Methods. 2007;42:321-424.

22. Pozzatti P, Loreto ES, Lopes PG, Athayde ML, Santurio JM, Alves SH. Comparison of the susceptibilities of clinical isolates of Candida albicans and Candida dubliniensis to essential oils. Mycoses. 2010;53:12-15.

23. Amaechi BT, Higham SM, Edgar WM. Techniques for the production of dental eroded lesions in vitro. J Oral Rehabil. 1999;26:97-102. 24. Loures FV, Levitz SM. XTT Assay of Antifungal Activity. Bio Protoc. $2015 ; 5: \mathrm{e} 1543$.

25. Holetz FB, Pessini GL, Sanches NR, Cortez DA, Nakamura CV, Filho BP. Screening of some plants used in the Brazilian folk medicine for the treatment of infectious diseases. Mem Inst Oswaldo Cruz. 2002;97:1027-1031.

26. Rabin N, Zheng Y, Opoku-Temeng C, Du Y, Bonsu E, Sintim HO. Biofilm formation mechanisms and targets for developing anti-biofilm agents. Future Med Chem 2015;7:493-512.

27. Ferreira GL, Pérez AL, Rocha IM, Pinheiro MA, de Castro RD, Carlo HL, et al. Does scientific evidence for the use of natural products in the treatment of oral candidiasis exist? A systematic review. Evid Based Complement Alternat Med. 2015;2015:147804.

28. Fürst R, Zündorf I. Evidence-Based Phytotherapy in Europe: Where Do We Stand? Planta Med. 2015;81:962-967.

29. Celerino de Moraes Porto IC, Chaves Cardoso de Almeida D, Vasconcelos Calheiros de Oliveira Costa G, Sampaio Donato TS, Moreira Nunes L, Gomes do Nascimento T, et al. Mechanical and aesthetics compatibility of Brazilian red propolis micellar nanocomposite as a cavity cleaning agent. BMC Complement Altern Med. 2018;18:219.
30. Oliveira JA, da Silva IC, Trindade LA, Lima EO, Carlo HL, Cavalcanti AL, et al. Safety and Tolerability of Essential Oil from Cinnamomum zeylanicum Blume Leaves with Action on Oral Candidosis and Its Effect on the Physical Properties of the Acrylic Resin. Evid Based Complement Alternat Med. 2014;2014:325670.

\section{Conflicts of interest}

The authors declared that they have no conflicts of interest. 